\title{
A retórica de Tapiiraiauara ou considerações para uma análise tensiva da alusão
}

Dilson Ferreira da CRUZ (FFLCH-USP)

RESUMO: Obter a adesão do interlocutor é o propósito de todo retórico e também do narrador de Tapiiraiauara, de Guimarães Rosa. À mão de linguagem, por equivalência de afetos, ele obtém seu intento. A semiótica tensiva auxilia a explicar sua ventura ao mostrar que a persuasão envolve, com frequiência, um jogo tensivo de ausências e presenças.

PALAVRAS-CHAVE: alusão; Guimarães Rosa; retórica, semiótica; tensividade

RÉSUMÉ: L'obtention de l'adhésion de l'interlocuteur est le propos de l'ancien rhéteur et aussi du narrateur de Tapiiraiauara, récit de Guimarães Rosa. La sémiotique tensive contribue pour expliquer son succès en démontrant que la persuasion concerne suivant un jeu tensive entre l'absence et la présence.

MOTS-CLÉS: allusion, Guimarães Rosa, rhétorique, sémiotique, tensivité 
Em seu Manuel Classique pour l'étude des tropes ou éléments de la science du sens des mots, de 1830, Pierre Fontanier define as figuras de expressão por reflexão como o estabelecimento de uma relação entre as idéias enunciadas e aquelas que não o são. Segundo o autor, fazem parte desse grupo, por exemplo, a hipérbole, a lítotes, a reticência e a alusão, objeto deste trabalho.

A análise do discurso tem mostrado que essas figuras implicam um jogo polifônico no qual uma voz afirma a idéia enunciada e outra voz expõe, como que pelo silêncio, a idéia não enunciada. Por exemplo, na reticência haveria uma voz que calaria e outra, em surdina, que expressaria o que a primeira não afirmou. Embora esse modelo explique o funcionamento dessas figuras em um nível discursivo, gostaríamos de investigar a alusão em um nível mais profundo e, para tanto, buscaremos utilizar o instrumental oferecido pela semiótica dita tensiva. Tal decisão se justifica pelo fato de haver nessas figuras de retórica um jogo tensivo de presenças e ausências, o qual não é explicado satisfatoriamente pela categoria da junção, uma vez que esta assume posições discretas (conjunção ou disjunção) ao passo que a presença, tal como proposto pela semiótica tensiva, trabalha com posições contínuas.

A alusão é definida por Fontanier (1997, p. 125) como figura que consiste em fazer sentir - e como veremos adiante, a expressão é particularmente feliz — a relação existente entre uma coisa dita e outra não dita. Essa relação é reveladora, justamente, da idéia que se quer exprimir. Por exemplo, o título do penúltimo romance de Machado de Assis é Esaú e Jacó apesar de não haver na trama personagens com tais nomes, de a ação se passar entre o final do Segundo Império e início da República e de não existir na trama qualquer conotação religiosa. Sim, o título alude à narrativa bíblica homônima, mas para que tal alusão seja compreendida é preciso se evidencie a relação que une os dois textos Uma explicação é o fato de os filhos de Isaque, assim como Pedro e Paulo do romance de Machado serem gêmeos e, como estes, terem-se tornado rivais irreconciliáveis ${ }^{i}$. A alusão ao episódio bíblico é ainda reforçada quando o "editor" do romance e autor da Advertência comenta a escolha do título.

[...] Quanto ao título foram lembrados vários, em que o assunto se pudesse resumir, Ab ovo, por exemplo, apesar do latim; venceu, porém, a idéia de lhe dar estes dous nomes que o próprio Aires citou uma vez:

Esaú e Jacó

Obra Completa, vol. III, p. 946- grifo meu.

Diante da alusão, e de o narrador informar que busca por um título que resuma o assunto do romance, é natural que o enunciatário passe a se questionar sobre o conteúdo comum às duas narativas e assim descubra que este não é outro senão a rivalidade entre os dois pares de gêmeos, protagonistas das duas narrativas.

Por outro lado, os nomes dos protagonistas de Esaú e Jacó (Pedro e Paulo) fazem alusão ainda a outra rivalidade bíblica, a existente ente entre o discípulo Pedro e o apóstolo Paulo. O primeiro defendia que cristianismo devia preservar algumas tradições judaicas enquanto o segundo advogava a ruptura total entre uma e outra doutrina ii. Já o Pedro do romance de Machado defendia a continuidade; no caso, a monarquia, enquanto Paulo se batia pela ruptura; logo, a república. Enfim, a relação 
entre as três duplas citadas - Esaú e Jacó, o apóstolo Paulo e o discípulo Pedro, e os gêmeos Pedro e Paulo - se estabelece pelo antagonismo e pela fraternidade ${ }^{\mathrm{iii}}$, sendo que os dois Pedros defendem a permanência e os dois Paulos, a transformação. Como se vê, essas duas idéias são expressas por meio da alusão, sem que seja necessário mencioná-las de forma explícita.

Enfim, pela alusão, uma idéia, um fato, inicialmente ausente (por exemplo, o antagonismo e a fraternidade) passa paulatinamente a se fazer presente e assim faz com a outra idéia (por exemplo, a religiosidade) tenha seu brilho diminuído e sua presença enfraquecida. Alusão não acarreta o desaparecimento total da presença antiga, mas provoca um balanceamento de presenças, as quais, como ensina a semiótica tensiva, se decompõem em foco e apreensão.

Como se sabe, o foco é a relação afetiva que liga o sujeito aos objetos do mundo, ao passo que a apreensão consiste na percepção que o mesmo sujeito tem da morfologia desses objetos. A alusão atua de modo a fazer com que o foco e a apreensão do sujeito se alterem, pois, conforme as palavras de Fontanier vistas ainda agora, essa figura faz sentir a relação entre uma presença e uma ausência e assim promove um rearranjo do foco e da apreensão do sujeito em relação aos seres do mundo. Essa figura de retórica funciona, enfim, como um operador da percepção do enunciatário, a qual, ao ser alterada pela linguagem, faz com que os mesmos fatos sejam vistos de outra perspectiva.

Com o objetivo de compreender melhor os mecanismos envolvidos na alusão e buscando, para tanto, utilizar o ferramental teórico oferecido pela semiótica tensiva, procuraremos fazer uma breve leitura do conto Tapiiraiauara, de Guimarães Rosa, em que o narrador conta que em certa ocasião viu-se constrangido a participar da caçada a uma anta e seu filhote. Durante a busca condoeu-se dos animais, porém sem ter meios de convencer seu companheiro a desistir da empreitada. É então que se lembra de aludir ao caçador que o Brasil poderia entrar em guerra e que seu filho, que se encontrava em serviço militar, poderia ser convocado para a frente de batalha. Diante dessa imagem, a presença da anta na mente do caçador se esvai e o animal é poupado. Vejamos em detalhes como isso acontece.

$$
* * *
$$

A retórica descreve a alusão em um nível discursivo, mas não esclarece como ou por que essa figura surte o efeito desejado. Conforme ficou dito, nossa hipótese é que a alusão produz uma alternância de presenças, a qual faz com que um fato evidente, próximo, (a anta) fique esmaecido e distante no tempo e no espaço e que aquilo que era longínquo, futuro ou remoto (a participação do filho na guerra), seja manifestado e assim se torne eminente, adjacente. Recorde-se que o sujeito é definido por sua relação com o objeto, a qual - acrescenta a semiótica tensiva - não resulta de posições discretas, como conjunção e disjunção, mas contínuas, como graus ou densidades de presença. Ao alterar o modo de presença, ou melhor, a percepção que o sujeito tem do mundo a seu redor, a alusão altera também seu saber e, conseqüentemente, sua identidade modal, uma vez que, como propõem Greimas \& Courtés (1993: p. 291), “a 
oposição categorial presença / ausência surge como uma possibilidade de distinguir dois modos de existência semiótica".

No início do conto Tapiiraiauara, a presença da anta para o caçador, Iô Isnar, é nítida, apesar de ele ver apenas seu bruto rastro: aos quatro e três dedos, dos cascos calcados no sulco fundo do carreiro largo. Iô Isnar regozija-se com o animal e o descreve para seu interlocutor: a carne é igual à da vaca: lombo, o coração, fígado... o couro é cabedal bom, rijo grosso. Repare que a descrição não é apenas extensa em termos da morfologia da anta, mas deixa entrever o afeto, como indica o verbo regozijar. Ambos, foco e apreensão, mostram-se, assim, intensos, criam uma excitação em torno da possibilidade do encontro com o animal e contribuem para o estabelecimento do estado passional de Iô Isnar. Por isso, para o narrador, havia urgência, eram horas episódicas, caso queira salvar o animal.

O narrador sabe que Iô Isnar tem um problema noutro nível, de dó e circunstância, viril compungência. Como ficou dito, seu filho achava-se na cidade em serviço militar, fato que, aliado à guerra, inquietava o caçador, ainda que no momento ele se preocupasse apenas com a caçada. O narrador conta que o parceiro sempre o inquiria a respeito da guerra, expondo a balda: "Haverá mais guerra? O Brasil vai?" Ao lado de uma morte quase realizada, pois a anta estava, nos dizeres do narrador, condenada viva, encontra-se outra morte, virtualizada, pois a possibilidade do filho ir à guerra já se fazia presente há muito na mente do Iô Isnar, mas noutro nível, enfraquecida. A percepção desse fato é longínqua e pertence ao futuro: haverá?... $\mathrm{O}$ Brasil vai?... O modo de presença da morte do filho é indicado ainda pelos adjetivos empregados pelo narrador: seu problema era de circunstância, definida por Houaiss como "qualidade, acidente ou atributo que cerca ou está anexo a fato [...] para, eventualmente, mudar-lhe a própria natureza ou substância”. Ora, o que é eventual pode ocorrer ou não, tem, portanto, uma existência virtual.

A presença da anta e do filho em relação a Iô Isnar pode ser decomposta em termos temporais e espaciais. Utilizando a descrição que o narrador faz das duas presenças, chega-se ao quadro abaixo, elaborado com base nas sugestões de Fontanille e Zilberberg (1998: 94). Contrapondo-se os actantes, o tempo e o espaço, conclui-se que a presença da anta na passagem citada é plenamente realizada e a do filho, virtualizada:

Quadro 1: comparação das presenças da anta e do filho

\begin{tabular}{|l|c|c|}
\hline & Anta (presença realizada) & Filho (presença virtualizada) \\
\hline Relação sujeito / objeto & Irrupção, aparição súbita & hábito, previsibilidade \\
\hline Tempo & iminência & Futuro \\
\hline Espaço & proximidade & Longínquo \\
\hline
\end{tabular}

Observe que nem a anta nem o filho estão fisicamente presentes, mas as duas ausências presentificam-se na mente do caçador de modos diferentes. $\mathrm{O}$ encontro com o tapir é visto como iminente; o sujeito sente que o animal está próximo; seu surgimento é esperado a qualquer momento como uma aparição súbita. Já a ida do filho à guerra é sempre colocada no futuro e a batalha, como algo distante. Em que pese o sofrimento que tal fato possa causar ao caçador, a possibilidade da guerra pertence à esfera da 
previsibilidade, mas a presença da anta, ainda que esperada, faz parte do repente. Conforme veremos, o narrador irá alterar o campo de percepção do caçador ao mudar o status de cada uma dessas duas presenças.

De acordo com Fontanille \& Zilberberg (1998: p. 92), o campo de presença do sujeito (domínio espaço-temporal onde ocorre a percepção) é definido pelos objetos do mundo que nele penetram ou que dele se afastam, o que faz com que esse campo oscile permanentemente, de acordo com essas idas e vindas. Por sua vez, a presença de cada objeto no interior do campo está associada à extensão da apreensão e à intensidade do foco que o sujeito tem deles. Uma vez que a presença é um contínuo que se articula em foco e apreensão, que estes variam da atonia à tonicidade total, e lembrando ainda que o foco está ligado ao afeto enquanto a apreensão ao "conteúdo" dos objetos, (Fontanille: 1998, p. 37-9), conclui-se que a oscilação do campo de presença está relacionada à variações tensivas da ordem do afeto e do cognitivo, as quais terão implicações para o estado passional do sujeito e para sua relação com o mundo que o cerca. Enfim, a variação de tonicidade do foco e da apreensão permitem depreender modalidades tensivas da presença, como se observa no esquema abaixo (cf. Fontanille e Zilberberg, 1998: p. 96):

Quadro 2: Modalidades da presença

\begin{tabular}{|c|c|c|c|}
\hline \multirow{2}{*}{} & \multicolumn{2}{|c|}{ Foco } \\
\cline { 2 - 4 } & Tonica & $\begin{array}{c}\text { Presença realizante } \\
\text { (Plenitude) }\end{array}$ & $\begin{array}{c}\text { Presença potencializante } \\
\text { (Inanidade) }\end{array}$ \\
\cline { 2 - 4 } Apreensãono & Átona & $\begin{array}{c}\text { Presença atualizante } \\
\text { (Falta) }\end{array}$ & $\begin{array}{c}\text { Presença virtualizante } \\
\text { Vacuidade }\end{array}$ \\
\hline
\end{tabular}

Assim, como se pode ver acima, um foco e uma apreensão tônicos conduzem a uma plena presença dos objetos, considerada realizante, tal como é a da anta no início do conto. Já foco e apreensão átonos, como a do filho, correspondem a uma presença "vazia", virtualizante. Por outro lado, uma apreensão átona diante de um foco tônico seria associada à falta, logo seria atualizante. Finalmente, um foco átono acompanhado de uma apreensão tônica seria potencializante. A análise do conto mostrará, espera-se, a realização desses movimentos.

Em um primeiro momento, o campo de percepção de Iô Isnar é fechado, pois nele intensidade e extensidade convergem (foco e apreensão são tônicos), indicando que a presença da anta é plena, enquanto a do filho é virtual, pois, nesse caso, tanto a apreensão quanto o foco, igualmente convergentes, são átonos. Lembremos que o narrador conta que Iô Isnar perguntava muito sobre a guerra, expondo a balda. Segundo Houaiss, balda é uma ação habitual; defeito ou hábito arraigado; mania e nos jogos indica uma carta sem valor para o jogo... Ora, o pouco valor pode ser usado como indicativo da uma baixa tensão, como é o caso de uma presença virtualizada (ver quadro 2). A missão do narrador não será outra senão alterar essa situação; inverter as posições para fazer com que o caçador desvie sua atenção da anta e passe a preocupar-se com o filho, poupando, assim, o animal. Daí o papel da alusão. Era preciso, portanto, menear 
caçador, agi-lo nesse propósito, à mão de linguagem em farsamento, súbito estudo, por equivalência de afetos... A pingo de palavras, com inculcações, em ordem a atordoá-lo. A idéia é aludir ao filho e assim fazer com que aumente do foco do caçador nele e que sua presença passe de virtual a atual. Consequentemente, o foco na anta se reduzirá e sua presença deixará de ser plena para ser inane, criando, assim, uma possibilidade para que o animal se salve. Urgia, portanto, alterar o campo de presença do caçador pela linguagem. Mas como, se o filho está na cidade e a anta ali, apenas a mil passos, no brejo-de-buritus?

Como explicam Fontanille e Zilberberg (1998: p. 97-8), a percepção pode ser articulada ao conjunto das modalizações existenciais do discurso, as quais podem ser construídas a partir de gradientes de ausência e presença. A significação, segundo os autores, aconteceria entre dois extremos que são, de um lado, a presença plena do mundo natural; no caso, a anta, a floresta, o brejo, e, de outro, a ausência do mundo interior do mesmo sujeito (o vazio de articulações), onde habita seu filho e a ameaça da guerra. Entre um extremo e outro, a significação alimenta-se de todos os graus de modalização. A existência semiótica fundar-se-ia, portanto, na busca de um equilíbrio tensivo entre os diferentes modos de existência que organizam o campo perceptivo do sujeito e condicionam a emergência da semiose discursiva. É com o objetivo de alterar a relação tensiva entre o mundo exterior do sujeito e seu mundo interior que o narrador passa a ministrar com opinião de martelo e prego a presença do filho. Ao longo de alguns minutos, entremeados da narrativa da caça, trava-se o seguinte diálogo:

[narrador] — Sim, o Brasil mandará tropas...

- Cruz! - ele [o caçador] fez, encolhera elétrico os ombros.

- É grave Luta distante contra malinos pagãos, conchinchins, indochins: que martirizavam os prisioneiros miudamente matavam. Guerra de durar anos.

Iô isnar, voz ingrata, já ele em outras oscilações:

- Deveras. - coçou a nuca, conquanto. Acelerava seu sentir; pôr-se cinco rugas na testa, como uma pauta de música. [...]. Ele era um retrato.

Tomei uns minutos

— "Seu filho único..." Disse. Do ominoso e torvo, de desgraçados sucessos, o parar em morte, os suplícios mais asiáticos. — "Se a sorte sair em preto..." - o tema fundamental. (Tutaméia, p. 172-3)

O que o narrador faz, basicamente, é abrir o campo de presença do caçador para, por meio da linguagem, introduzir a presença do filho. Desse modo, passam a fazer parte de seu campo de presença tudo o que o Iô Isnar conseguir focar. O seu mundo interior agora não está mais vazio e rivaliza com o pleno de expressão do mundo exterior. Mais concretamente, o caçador passa a sentir a falta do filho. Ocorre que a falta é atualizante, pois sendo o foco tônico (e ligado ao afeto, no caso, do caçador ao filho) e a apreensão, átona, Iô Isnar desencadeia uma busca para aprender tudo o que consegue focar e, assim, voltar a igualar foco e apreensão. Observe que essa é a bem sucedida aposta do narrador. Um dos indícios da ocorrência de um déficit de apreensão 
é justamente o fato de o caçador buscar compensá-lo por meio informações sobre a guerra. A alternativa seria abandonar esse percurso e reduzir novamente o foco, por exemplo, tentando esquecer aquilo de que foi lembrado. As marcas da escolha do caçador pelo primeiro percurso estão nas suas reações somáticas:

Iô Isnar - a boca aberta ainda maior, porque levantara a cabeça — e um olhar homicida. Malhava-me fogo?

Só futuras sombras não logravam, porém o desandamento de um cru caçador, seu coração a desarrazoar-se. Talvez a menção prática de providências vingasse sacudi-lo: — "Ajudo-o... Mas tem de vir comigo à cidade..."-propinei. (Tutaméia, p. 173)

Claramente, vê-se que a tensão de Iô Isnar aumentara em relação ao filho, mas, como o próprio narrador reconhece, só sombras futuras não seriam suficientes para desarrazoá-lo. Assim, o narrador aposta no desejo que tem Iô Isnar de aumentar a apreensão e o manipula por tentação: Ajudo-o... Mas tem de vir comigo à cidade. Lembremos que a apreensão está mais ligada a aspectos cognitivos; logo, ir à cidade significaria, ao menos em tese, a possibilidade de um maior saber e assim igualar apreensão e foco, o que inevitavelmente produz a redução do foco na anta, como indicam outras reações somáticas do caçador:

Iô Isnar sumiu a cor do rosto, perdera o conselho; o queixo trêmulo, Valha-o a breca! Operava, o método. Vinha-se lhe ao extremo dos dedos o pânico, das epidermes psíquicas. Ele estava de um metal. Era maquinalmente meu. Obra de uns dez minutos. (Tutaméia, p.173)

O sumiço da cor do rosto, a perda do conselho, o pânico indicam uma primeira perda de densidade de presença do mundo natural que cerca Iô Isnar, resultado, justamente, da redução do foco no mundo exterior, a qual, por sua vez, decorre do aumento do foco no filho. A apreensão do mundo natural ainda é tônica, afinal ele percebe dimensões, quantidades, limites que o caracterizam, mas este já não o afeta, pois o seu foco agora está no filho. O desbalanceamento entre foco e apreensão do caçador resulta, ainda, no seu descontrole e em sua cisão: um, é o sujeito do foco, que é tônico em relação ao filho, mas átono em relação ao mundo exterior; outro, é o sujeito da apreensão, a qual é átona em relação ao filho, mas ainda tônica em relação ao mundo. Esses dois sujeitos que até então permaneciam unidos estão agora dissociados.

Examinem-se os dois percursos da presença realizados por Iô Isnar em relação à anta e ao filho. No caso daquela, parte-se de uma presença plena, realizante, em que foco e apreensão são tônicos, para uma presença potencializante em que a apreensão é tônica, mas o foco é átono. No caso do filho, parte-se de uma presença virtualizante, em que foco e apreensão são átonos, para outra, atualizante, em que a apreensão continua átona, mas o foco agora é tônico. A combinação das duas novas situações leva Iô Isnar, em relação ao filho, a procurar por informações sobre a guerra e, no caso da anta, a uma perda de interesse pela caçada. Esses movimentos podem ser vistos no quadro a seguir: 


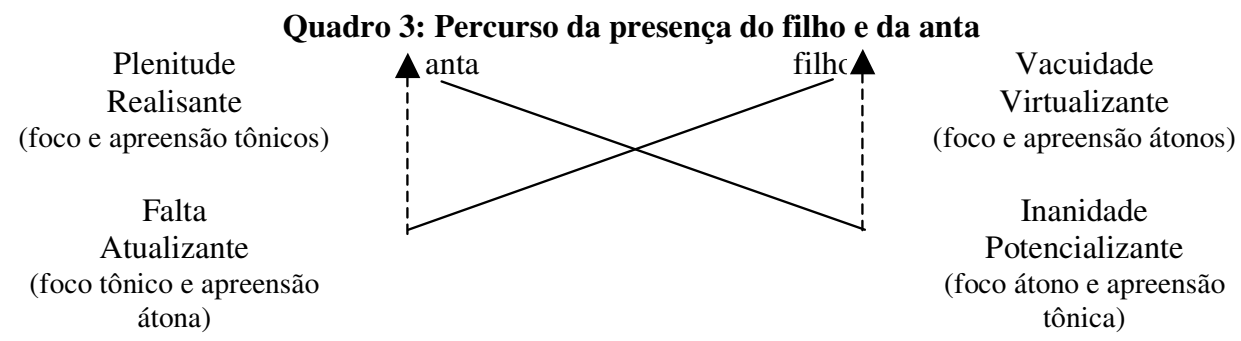

A presença da anta para o caçador deixou de ser plena para ser potencial, isto é, passou a localizar-se em algum ponto entre a presença e ausência, mas com um foco átono e apreensão tônica. Com o filho aconteceu o processo inverso, em razão do aumento do foco: sua presença deixou de ser virtual para ser atualizante. Em síntese, a anta desloca-se da dêixis da presença para a da ausência e o filho desta para aquela. Esse movimento também pode ser expresso em termos de profundidade espacial e temporal (ver quadro 1). O tapir deixa de estar próximo do caçador e ao final do conto (supõe-se) torna-se distante. Com o filho o processo é oposto: ele deixa de estar distante, passa a ser familiar e se torna próximo com a urgência de impedir seu alistamento. Com o tempo não é diferente: a caçada da anta deixa de ser iminente, depois é adiada para se tornar, talvez, um projeto futuro. O filho, um fato antigo, (do ponto de vista do seu conhecimento) ou futuro (se considerada ida para a guerra), tem sua partida antecipada até se tornar iminente como então era o caso da anta. Abaixo reunimos as profundidades temporal e espacial da presença do filho e da anta e o processo envolvido na alusão:

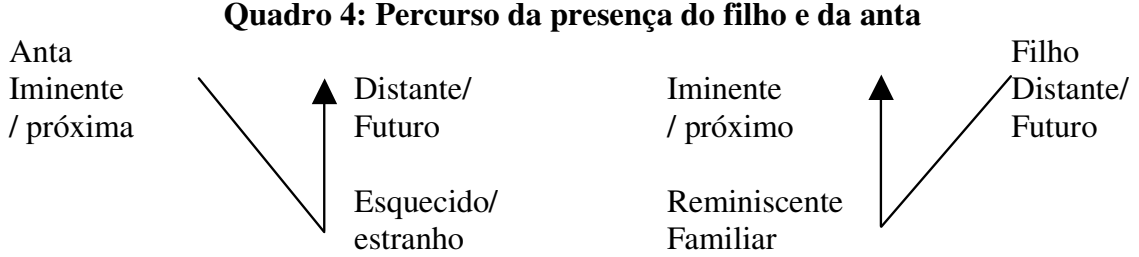

Em suma, como já havia indicado Fontanier, a alusão torna presente o que era ausente e atenua a presença do que até então era evidente, pois, mais uma vez, a presença se mostra relacional e tensiva: a presença de um objeto sempre depende da percepção do sujeito e da presença de outros objetos. Contudo, isso não explica de modo satisfatório porque a alusão pode contribuir para fazer o enunciatário mudar de idéia, razão de ser da retórica, portanto, do uso dessa figura.. Fontanille e Zilberberg (1998: p. 103) propõem que a presença seja desdobrada em três enfoques: primeiro, em relação aos atos perceptivos, como uma tensão maior ou menor entre foco e apreensão; segundo, do ponto de vista do alcance da percepção, como uma tensão entre a consciência do indivíduo e seu corpo; terceiro, como uma tensão maior ou menor entre os papéis que o compõem. Para cada um desses casos, postula-se que o sujeito se divida 
em dois: o sujeito do foco e o sujeito da apreensão, os quais mantém entre si uma relação que vai da tensão máxima, que conduz à re-união de ambos, até a tensão mínima, que leva à distensão e à separação total.

O mundo natural desempenha um papel importante na dinâmica que se estabelece entre os dois sujeitos. Assim, o sujeito cujo foco e apreensão forem convergentes e tônicos verá o mundo como uno e coeso e se apresentará como sujeito realizado, ou em termos passionais, exaltado, entusiasmado. Já o sujeito cujo foco for superior à apreensão tenderá ver o mundo de forma menos densa, como algo compactado, não plenamente unificado. Dir-se-á, então, que o sujeito, é atualizado e, em termos passionais, pode-se considerá-lo atento, alerta, pronto para entrar em ação, justamente devido ao diferencial entre apreensão e foco. Em uma situação contrária, isto é, em que o foco é inferior a apreensão, o mundo perderá um pouco mais de sua densidade e será visto como ainda mais distribuído. O sujeito consegue focar apenas uma parcela do mundo inferior àquela que ele apreende e por isso será considerado potencializado ou indiferente, frustrado, uma vez que o ato perceptivo não chegou a ser apreendido na proporção esperada (focalizada). Finalmente, o último caso é aquele em que a tensão total é praticamente nula, portanto, o foco e/ou a apreensão também o são. O sujeito torna-se, então, virtualizado. Nesse caso, o mundo é visto como difuso, pouco nítido e numeroso, como se não fosse mais possível constituir uma unidade. ${ }^{\text {iv }}$

No início do conto, quando o mundo é visto pelo caçador como uno e coeso, o narrador afirma que ele se regozijava; logo, esse estado é compatível com o estado de exaltação, de entusiasmo que caracteriza o indivíduo nessa condição. Em seguida, à medida que progride o fazer persuasivo do narrador, Iô isnar passa a apresentar oscilações passionais, características do sujeito cujo foco e apreensão não são equivalentes. As manifestações somáticas do caçador acompanham a evolução de seu estado de alma. Inicialmente, ele é descrito pelo narrador como carrasco, (que o dicionário considera um indivíduo enérgico), mas em seguida, à medida que o foco no filho supera a apreensão, ele começa a mostrar sinais de que está atento, pronto para entrar em ação, como indicam a, boca aberta, e o olhar homicida.... Por outro lado, no que diz respeito à anta, é a apreensão se torna superior ao foco e, consequentemente, o sujeito consegue apreender apenas uma parcela da realidade que percebe. O mundo já não é tão coeso e único como antes, mas como que começa a se dividir em dois: o da anta (ou da apreensão) e o do filho (ou do foco). O processo continua até que, com o seguir da argumentação, a apreensão do mundo também se anula, igualando-se ao foco e transformando em sujeito virtualizado. E justamente um dos indícios da redução da apreensão da realidade é que o caçador deixa escapar a oportunidade de caçar a anta:

Iô Isnar falhara, a cilada, o tiro; desexercera-se de mãos, não afirmara a vista.

[...]

Iô Isnar rezava, feito se moribundo, se derrubado, tripudiado pelo tapir, que defeca mesmo quando veloz no desembesto: seu esterco no chão parecia o de um cavalo. (Tutaméia, p. 173) 
Moribundo, derrubado, tripudiado é como o narrador descreve o sujeito no momento em que o mundo lhe parece de tal forma dividido que a densidade da presença quase desaparece. É sem duvida a situação do sujeito virtualizado que está separado de si próprio em virtude de ter que optar o pelo foco ou pela apreensão ou por ambos em nível muito baixo. Nessa situação, o caçador foi, literalmente, incapaz de apreender, de capturar a anta. O plano do narrador teve êxito.

A alusão cumpriu o seu papel, substituiu uma presença por outra e assim permitiu a adesão, a contragosto, do caçador às teses do narrador. Sim, praticamente não houve argumentação alguma e, a rigor, não se poderia dizer que Iô Isnar tenha sido persuadido a não matar o animal, mas que este foi excluído de seu campo de presença. No entanto, é justamente essa ausência de argumentação que nos interessa aqui, pois o processo radical de enfraquecimento do foco e da apreensão em um caso e seu fortalecimento em outro a tornou desnecessária. Naturalmente, na maior parte das vezes, não é assim que as coisas se passam e à alusão seguem-se vários argumentos conforme os fins do orador. Porém, entendemos que em muitos casos a alusão desempenha um papel fundamental na persuasão ao apresentar uma outra perspectiva da realidade e alterar o campo de presença do sujeito mediante seu povoamento por outras ausências e presenças. Ocorre, porém, que nesses casos o papel da alusão passa despercebido, dificultando seu estudo.

O conto de Rosa funciona, pois, como uma espécie de microscópio que a um só tempo amplia o processo de persuasão e o limita à parte correspondente à alusão. Se pudéssemos acompanhar a evolução do conto talvez víssemos Iô Isnar retornar com mais ou menos vagar à sua posição inicial, de sujeito concentrado diante de um mudo único e coeso. Nesse segundo momento, a presença dominante não seria mais a da anta, mas a do filho, conforme sugere sua concordância, implícita no conto, de acompanhar o narrador até a cidade para resolver o problema. No entanto, para que isso pudesse acontecer, foi preciso que a alusão funcionasse como um fator de desequilíbrio momentâneo com a introdução de uma nova presença e contribuindo, assim, para a realização da persuasão.

\section{REFERÊNCIAS BIIBLIOGRÁFICAS}

BíBLIA. Trad. João Ferreira de Almeida. Edição revista e atualizada. São Paulo e Barueri: Editora Cultura Cristã e Sociedade Bíblica do Brasil, 1999.

FONTANIER, Pierre. Les figures du discurs. Paris : Flammarion, 1977

Fontanille, Jacques. Sémiotique $d u$ discours. Limoges: Presse Universitaire de Limoges, 1998.

Fontanille, Jacques e Zilberberg, Claude. Tension et signification. Liège: Largada, 1998

GreIMAS, A. J. e COURTÉs, Joseph. Sémiotique, dictionnaire raisonné de la théorie du langage I. Paris: Hachette, 1979. 
Hoauiss. Antônio. Dicionário Houaiss da Língua Portuguesa. Rio de Janeiro: Objetiva, 2004.

Rosa, Guimarães. Tutaméia $5^{\mathrm{a}}$ ed. Rio de Janeiro: Livraria José Olympio Editora., 1979

\section{Como citar este artigo:}

CRUZ, Dilson Ferreira da. A retórica de "Tapiiraiauara" ou considerações para uma análise tensiva da alusão. Estudos Semióticos, Número 2, São Paulo, 2006. Disponível em <www.fflch.usp.br/dl/semiotica/es >. Acesso em "dia/mês/ano".

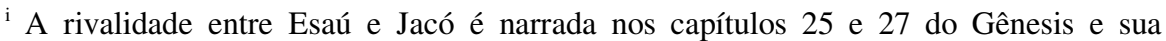
conciliação, no capítulo 33. Contudo, trata-se, provavelmente, de uma meia conciliação, uma vez que há dúvidas sobre a sinceridade de ambos (versículos 12 a 17 deste capítulo). Além disso, depois desse momento os dois irmãos nunca mais voltaram a se encontrar.

ii Paulo narra sua disputa doutrinária com Pedro na epístola aos Gálatas (1:10-2:14). Lucas também discute o assunto no livro dos Atos dos Apóstolos (15: 1-34) ao comentar primeiro concílio da igreja, que, em síntese, discutiu se as tradições judaicas deveriam ou não ser adotadas pelo cristianismo.

iii Pedro e Paulo no Novo Testamento eram irmãos em virtude da fé comum que professavam.

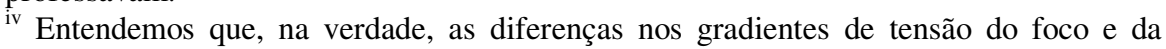
apreensão é que tornam a presença do mundo diferenciada para o sujeito e não o contrário, como propõem Fontanille e Zilberberg (1998: p. 104). Além disso, o mundo se apresentaria em níveis semelhantes de densidade existencial tanto para o sujeito atualizado quanto o sujeito potencializado, mas a diferença entre um estado e outro seria decorrente do fato de no primeiro caso o foco ser superior a apreensão havendo, então, a instalação de uma falta que leva o sujeito a ver o mundo como desprovido de consistência, despovoado. No segundo caso, sendo a apreensão maior que o foco, haveria como que um excedente de presença que levaria o sujeito a considerar o mundo como "maciço", isto é, feito de matéria compacta, cerrado, denso.
} 